\title{
Cigarette smoking and smoking- attributable diseases among Estonian physicians: a cross-sectional study
}

\author{
Mait Raag ${ }^{*}$ (i) and Kersti Pärna
}

\begin{abstract}
Background: Smoking is a risk factor for several diseases. Physicians are role models for their patients. Physicians who smoke underestimate the health risks of smoking and may be less likely to offer advice to help their patients to quit. The aim of this study was to: provide an overview of smoking behaviour among Estonian physicians; assess the relationship between smoking and ischaemic heart disease (IHD), chronic bronchitis (CB), and lung emphysema (LE); and estimate fractions of prevalences of the three diseases attributable to smoking.
\end{abstract}

Methods: Self-administered questionnaires were sent to practising physicians $(n=5666)$ in Estonia in 2014. Prevalence of smoking and relative risks for IHD, CB and LE as well as the risks of IHD, CB and LE attributable to smoking were calculated by age and sex. Post-stratification was used to compensate non-response.

Results: There were 535 male and 2404 female physicians participating. The prevalence of daily smoking was $12.4 \%$ (95\% Cl 10.4-14.4\%) among men and 5.0\% (95\% Cl 4.4-5.6\%) among women. Mean duration of smoking among male and female daily smokers was $28.6(95 \% \mathrm{Cl} 26.1-31.1)$ and $28.6(95 \% \mathrm{Cl} 27.1-30.2)$ years. Compared to lifelong non-smokers, the age-adjusted risk for IHD was 1.29 times ( $95 \% \mathrm{Cl}$ 0.88-1.89) higher for men, but 1.69 times (95\% Cl 1.17-2.40) lower for all women who have ever smoked. The risk for CB was 2.29 (95\% Cl 1.30-4.03) times higher for smokers among men and, 1.32 (95\% Cl 0.95-1.82) among women; the risk ratio for $L E$ was 4.92 (95\% Cl 1.14-21.1) among men and 2.45 (95\% Cl 0.63-9.52) among women. The smoking-attributable risk for IHD was 3.2\% (95\% Cl 2.3-4.1\%) among men and -0.1\% (95\% Cl $-0.7-0.4 \%)$ among women; for CB 6.9\% (95\% Cl 6.0-7.8\%) and 4.2\% (95\% Cl 3.5-4.8\%); and for LE 18.8\% (95\% Cl $17.0-22.5 \%)$ and $22.6 \%(95 \% \mathrm{Cl} 18.5-26.9 \%)$, respectively.

Conclusion: Prevalence of daily smoking was relatively low among Estonian physicians (and twice lower among female physicians). The risk attributable to smoking was higher for LE and CB than for IHD.

Keywords: Physicians, Tobacco smoking, Attributable risk, Ischaemic heart disease, Chronic bronchitis, Lung emphysema, Chronic obstructive pulmonary disease, Estonia

\section{Background}

Tobacco smoking is a major risk factor for cardiovascular diseases [1-3], including ischaemic heart disease (IHD) [4-6], and for pulmonary diseases, including chronic obstructive pulmonary disease (COPD) which is usually preceded by chronic bronchitis (CB) and is often manifested as obstructive bronchitis with lung emphysema (LE) [7, 8]. Effective tobacco control reduces the

\footnotetext{
*Correspondence: mait.raag@ut.ee

Institute of Family Medicine and Public Health, University of Tartu, Tartu, Estonia
}

incidences of the related diseases.

Physicians are widely regarded as health behaviour role models [9-11]. At the same time, physicians who smoke underestimate the health risks of smoking and may be less likely to offer advice to help their patients quit smoking [12-14].

Previous reports have shown that smoking prevalence among physicians in high income countries (e.g. the United Kingdom, the United States, Australia, and Finland) has decreased [15-18]. The prevalence of 
smoking among physicians was 4\% in US in 1984 and 3\% in Australia in 1996 already [15]. In Finland, the prevalence of smoking was 5\% among male and 3\% among female physicians in 2001 [19]. In Estonia, surveys concerning smoking among physicians have been carried out four times (1978, 1982, 2002, 2014), with smoking having decreased since 1982 (age standardized prevalence of daily smoking has decreased from 19 to 7\%) [20].

Smoking prevalence in the total population in developed countries (including Estonia) has decreased during recent decades as well [21]. In Estonia, daily smoking among the general adult population (16-64-years olds) decreased from $50 \%$ in 1994 to $31 \%$ in 2014 among men and from 21 to $16 \%$ among women [22, 23]. As it has been suggested that the decrease in smoking among doctors is followed by the decrease in smoking in the general population [24, 25], it is beneficial to monitor physicians' smoking habits to understand the current and future tobacco epidemic situations in the region.

Many studies have shown that smoking increases the risk of heart and lung diseases [1-6]. In 2015, diseases attributable to smoking had the second highest ranking among all of the diseases burdening people globally [26]. Measured in disability-adjusted life years (DALYs), tobacco smoke was associated with $24 \%$ of DALYs caused by IHD and $44 \%$ of DALYs caused by COPD [27]. However, the risk of a disease that is attributable to smoking depends both on the prevalence of smoking and the strength of the association between smoking and the occurrence of the disease. For example, in 2010 the prevalence of daily smoking (in 15-year olds or above) was $23 \%$ in Ukraine and Italy and $39 \%$ in Albania [21], but $59 \%$ of DALYs caused by COPD were associated with tobacco smoke in Ukraine, $62 \%$ in Albania and $71 \%$ in Italy [27]. Therefore, if calculated for one population, the smoking-related burden on health is not easily conveyable to another.

To our knowledge no-one has estimated the proportions of prevalence of IHD, CB and LE attributable to smoking before, neither among physicians nor among the general population in Estonia. The aim of this paper was to provide an overview of smoking behaviour among Estonian physicians; assess the relationship between smoking and IHD, CB, and LE; and estimate fractions of prevalences of the three diseases attributable to smoking.

\section{Methods}

\section{Study conduct}

We conducted a cross-sectional study with total sampling, the conduct of which is described in detail elsewhere [28]. All physicians working in Estonia are registered in the Estonian Health Care Professionals
Registry [29]. The registry was queried for practising physicians in July 2014 and the data was linked with the population registry to obtain the physicians' home addresses. In October 2014, study materials were sent to all physicians with a known home address $(n=5666)$. The four-page questionnaire was similar to that which was used in the previous 2002 study on smoking among Estonian physicians, which had been adapted from a questionnaire originally developed by the World Health Organization [30]. A reminder letter was sent to those who had not responded within 4 weeks, and study materials were sent again to those who still had not responded in the end of November 2014. The responses were accepted until March 2015.

Data on smoking behaviour and smoking related diseases The participants were asked if they had ever been smoking regularly at least for a year; their age of taking up smoking; and their current smoking behaviour. These questions allowed to define four categories: never smokers (who answered 'no' to the question asking about ever smoking regularly), ex-smokers (who answered 'yes' to the question asking about ever smoking regularly and 'no' to the question regarding current smoking), occasional smokers (who answered 'yes' to the question regarding current smoking and 'no' to the question regarding daily current smoking), daily smokers (who answered 'yes' to the question asking about daily current smoking).

Daily smokers were asked the number of cigarettes they smoked each day (up to $10,11-20,21-30$, or more than 30); therefore, only the proportions of daily smokers who smoke more than a pack (20 cigarettes) in a day is described and this information is not considered in further analysis.

A multiple-choice question was asked about currently having $\mathrm{IHD}, \mathrm{CB}$, or $\mathrm{LE}$; refusal to answer was an additional option. Anyone who did not choose from any of the options (including refusal to answer) was considered to be a person who does not have any of the afflictions.

\section{Statistical analysis}

To reduce bias caused by differential response rate (i.e. younger people and men being under-represented) poststratification weights (based on sex and 5-year age groups) were used to compensate unit non-response (non-returned or unfilled questionnaires) [31]. Unadjusted and age-adjusted risk ratios (RR) were estimated by log-binomial regression. Classical statistical methods assume infinite population, but as about a half of all physicians in Estonia participated in the study, finite population correction [31] increasing the precision of the estimates was applied to calculate Wald-type 95\% 
confidence intervals (CI). Agresti-Coull 95\% confidence intervals with finite population correction were calculated for zero proportions, based on the weighted estimate of the total size of the respective subpopulation. To account for multilevel exposure (four smoking categories), level-specific adjusted attributable risks (AR) were calculated, defined as

$$
A R_{k}=\sum_{s} \frac{\left[P\left(D \mid E_{k}, C_{s}\right)-P\left(D \mid E_{0}, C_{s}\right)\right] P\left(E_{k} \mid C_{s}\right) P\left(C_{s}\right)}{P(D)}
$$

where $P\left(D \mid E_{k}, C_{s}\right)$ is the proportion of diseased among individuals with exposure level $k(0=$ never smoker $)$ and confounder level $s, P\left(E_{k} \mid C_{s}\right)$ is the prevalence of exposure level $k$ among individuals with confounder level $s$, $P\left(C_{s}\right)$ is the prevalence of confounder level $s$, and $P(D)$ is the prevalence of disease [32]. The overall risk attributable to exposure to smoking was estimated by case-load method:

$$
A R=\sum_{k} w_{k} A R_{k}
$$

where $A R_{k}$ denotes AR specific to exposure level $k$ and $w_{k}$ equals the proportion of cases in level $k$ [33]. To account for finite population, $95 \%$ confidence intervals for AR were estimated using the replication bootstrap method [34]. Age was grouped to four groups based roughly on the quartiles in the target population. To adjust for years smoked, exposure was defined by the combination of smoking status and years smoked $(0-5$, $6-15,16-25,>25$ years).

EpiInfo 3.5.3 [35] was used for double data entry. Statistical environment R 3.2.2 [36] with survey package [37] was used for the calculations.

\section{Results}

\section{Target population and study participants}

In total, 2939 practising physicians (535 men and 2404 women) participated in this study. The crude response rate was $52 \%$, while the corrected response rate (excluding physicians who were unavailable, retired, had an incorrect address, had left Estonia, or had died) was $53 \%$. About four fifths $(79,6 \%)$ of the respondents lived in cities or towns.
The age of the study participants was between 24 and 86 . Men $(18 \%$ in the sample vs. $23 \%$ in the population) as well as younger physicians (mean age 51.7 years in the sample vs. 51.2 in the population) were slightly under-represented in the sample. The distribution of physicians by age groups and sex in the target population and the proportions participating in the study in each age-sex group is given in Table 1. Counts of physicians by sex, age, smoking status, years smoked, presence of IHD, CB and LE weighted by age and sex are given in Additional file 1.

\section{Prevalence and duration of smoking}

Current smokers (occasional and daily combined) constituted 8.4\% (95\% CI 7.6-9.1\%) of Estonian physicians. The prevalence of daily smoking was highest in the age group of 51-60 both among men and women (Table 2). Among male physicians $53.0 \%$ had never smoked, 31.5\% had quit smoking, 3.1\% smoked occasionally, and 12.4\% smoked daily. The respective proportions among female physicians were $74.5,19.2,1.3$, and $5.0 \%$. Among male daily smokers $11.4 \%$ (95\% CI 6.9-18.0\%) smoked at least 21 cigarettes per day, while among female daily smokers this proportion was 7.7\% (95\% CI 4.9-12.0\%).

In general, smoking behaviour by age groups was somewhat different between men and women (Table 2). Among physicians younger than 41 the prevalence of lifelong non-smoking was $10 \%$ higher in women compared to men, whereas among physicians older than 40 the difference was at least $25 \%$. In the youngest age group ( $\leq 40$ years), the proportion of ex-smokers was almost the same among men (12.7\%) compared to women (11.1\%), but not in the older age groups (the difference between men and women was $>10 \%$ ). The proportion of daily smokers ranged from $9 \%$ to $16 \%$ among men, but from $2 \%$ to $8 \%$ among women in all age groups.

In general, men had longer history of smoking than women (Table 3). Male ex-smokers had smoked 16.6 years, occasional smokers 17.1, and daily smokers 28.6 years on average. The corresponding numbers among women were 11.3, 14.4, and 28.6 years.

\begin{tabular}{|c|c|c|c|c|c|c|}
\hline \multirow[b]{2}{*}{ Age } & \multicolumn{3}{|c|}{ Target population (\% of all 5666 working physicians in Estonia) } & \multicolumn{3}{|c|}{ Participants (\% of age-sex group in the target population) } \\
\hline & $\overline{\text { Male }}$ & Female & Total & Male & Female & Total \\
\hline$\leq 40$ & $330(6 \%)$ & 1069 (19\%) & $1399(25 \%)$ & $123(37 \%)$ & $586(55 \%)$ & 709 (51\%) \\
\hline $41-50$ & $279(5 \%)$ & $924(16 \%)$ & $1203(21 \%)$ & $118(42 \%)$ & $492(53 \%)$ & $610(51 \%)$ \\
\hline $51-60$ & $344(6 \%)$ & $1190(21 \%)$ & $1534(27 \%)$ & $125(36 \%)$ & $641(54 \%)$ & $766(50 \%)$ \\
\hline$\geq 61$ & $330(6 \%)$ & $1200(21 \%)$ & $1530(27 \%)$ & $170(52 \%)$ & $684(57 \%)$ & $854(56 \%)$ \\
\hline Total & $1283(23 \%)$ & 4383 (77\%) & 5666 (100\%) & $536(42 \%)$ & $2403(55 \%)$ & 2939 (52\%) \\
\hline
\end{tabular}

Table 1 Age-sex distribution of the target population and study participants of the survey among physicians in Estonia 
Table 2 Prevalence of smoking ( $95 \%$ Cl) by sex and age group among physicians in Estonia (population estimates)

\begin{tabular}{|c|c|c|c|c|c|}
\hline Sex & Age & Never smokers & Ex-smokers & Occasional smokers & Daily smokers \\
\hline \multirow[t]{5}{*}{ Male } & $\leq 40$ & $74.9(69.6-80.2)$ & $12.7(8.7-16.8)$ & $3.2(1.0-5.3)$ & $9.2(5.6-12.8)$ \\
\hline & $41-50$ & $52.6(46.4-58.9)$ & $35.9(29.8-41.9)$ & $1.7(0.1-3.4)$ & $9.8(6.1-13.5)$ \\
\hline & $51-60$ & $41.5(35.5-47.5)$ & $35.2(29.4-41.0)$ & $7.2(4.1-10.3)$ & $16.1(11.6-20.5)$ \\
\hline & $\geq 61$ & $43.5(38.2-48.9)$ & $42.3(37.0-47.7)$ & $0.0(0.0-2.2)$ & $14.1(10.2-18.0)$ \\
\hline & Total & $53.0(50.0-56.0)$ & $31.5(28.7-34.2)$ & $3.1(2.0-4.2)$ & $12.4(10.4-14.4)$ \\
\hline \multirow[t]{5}{*}{ Female } & $\leq 40$ & $85.0(83.0-87.0)$ & $11.1(9.3-12.9)$ & $1.5(0.8-2.2)$ & $2.4(1.6-3.3)$ \\
\hline & $41-50$ & $77.5(75.0-80.1)$ & $17.0(14.7-19.3)$ & $2.0(1.2-2.9)$ & $3.5(2.4-4.6)$ \\
\hline & $51-60$ & $66.8(64.3-69.3)$ & $24.1(21.8-26.4)$ & $1.1(0.5-1.7)$ & $8.0(6.5-9.4)$ \\
\hline & $\geq 61$ & $70.5(68.1-72.9)$ & $23.2(21.0-25.4)$ & $0.7(0.3-1.2)$ & $5.6(4.4-6.8)$ \\
\hline & Total & $74.5(73.3-75.7)$ & $19.2(18.1-20.3)$ & $1.3(1.0-1.6)$ & $5.0(4.4-5.6)$ \\
\hline Total & & $69.7(68.5-70.9)$ & $21.9(20.9-23.0)$ & $1.7(1.4-2.0)$ & $6.7(6.0-7.3)$ \\
\hline
\end{tabular}

Prevalence and relative risk of IHD, CB, and LE

There were 762 physicians (25.9\% of the sample) who did not wish to respond to the diseases-related questions. Among the rest $(n=2177)$, there were 122 IHD cases (77 among never smokers), 106 CB (55 among never smokers), and $11 \mathrm{LE}$ cases (3 among never smokers).

In general, the risk of these three diseases was lowest among never smokers. Overall IHD prevalence was 5.3\% (95\% CI 4.7-6.0\%); $4.5 \%$ (95\% CI 3.8-5.2\%) among never, $7.0 \%$ (95\% CI 5.3-8.6\%) among ex-, 7.4\% (95\% 0.6-14.2\%) among occasional, and 7.0 (95\% CI 3.9$10.2 \%)$ among daily smokers. Overall CB prevalence was 4.8\% (95\% CI 4.2-5.4\%); 3.4\% (95\% CI 2.8-4.0\%) among never, 5.9\% (95\% CI 4.4-7.4\%) among ex-, 3.8\% (95\% CI 0.0-8.9\%) among occasional, and $17.7 \%$ (95\% CI $12.8-$ $22.6 \%)$ among daily smokers. Overall LE prevalence was 0.6\% (95\% CI 0.4-0.8\%); 0.2\% (95\% CI 0.0-0.3\%) among never, $1.6 \%$ (95\% CI 0.8-2.5\%) among ex-, 0\% (95\% CI $0.0-0.0 \%$ ) among occasional, and $1.2 \%$ (95\% CI $0.0-$ $2.8 \%)$ among daily smokers.

Table 3 Average duration of smoking in years ( $95 \% \mathrm{Cl}$ ) by sex and age group among physicians in Estonia (population estimates)

\begin{tabular}{lllll}
\hline Sex & Age & Ex-smokers & Occasional smokers & Daily smokers \\
\hline Male & $\leq 40$ & $8.1(6.6-9.6)$ & $12.2(10.7-13.8)$ & $9.7(7.8-11.6)$ \\
& $41-50$ & $15.1(13.5-16.6)$ & $15.5(5.5-25.5)$ & $22.5(19.7-25.4)$ \\
& $51-60$ & $14.9(12.9-16.9)$ & $19.4(13.9-25.0)$ & $30.0(26.4-33.7)$ \\
& $\geq 61$ & $21.8(19.6-24.0)$ & $-^{a}$ & $43.1(40.5-45.6)$ \\
& Total & $16.6(15.4-17.7)$ & $17.1(13.3-20.9)$ & $28.6(26.1-31.1)$ \\
Female & $\leq 40$ & $5.5(4.8-6.2)$ & $7.4(5.2-9.5)$ & $13.0(11.0-15.0)$ \\
& $41-50$ & $9.2(8.2-10.2)$ & $17.9(14.0-21.9)$ & $22.3(20.0-24.6)$ \\
& $51-60$ & $11.3(10.3-12.4)$ & $11.3(6.1-16.5)$ & $28.4(26.5-30.3)$ \\
& $\geq 61$ & $14.8(13.5-16.1)$ & $26.1(16.0-36.2)$ & $38.2(35.6-40.8)$ \\
& Total & $11.3(10.7-11.9)$ & $14.4(11.6-17.1)$ & $28.6(27.1-30.2)$ \\
Total & & $13.0(12.4-13.6)$ & $15.5(13.2-17.8)$ & $28.6(27.2-30.0)$ \\
\hline
\end{tabular}

${ }^{\mathrm{a}}$ Among the participants there were no men over 60 smoking occasionally
There was a clear trend of increasing prevalence of IHD and CB by age groups, the trend for LE prevalence was less visible due to a small number of cases (Fig. 1). Illustrating the effect of smoking, those trends were more pronounced among daily smokers compared to lifelong non-smokers. IHD was clearly more prevalent among men than women.

Relative risks for the three diseases comparing smokers to non-smokers were higher among men than among women. Compared to lifelong non-smokers, the age-adjusted risk for IHD was 1.29 times (95\% CI $0.88-$ 1.89) higher for all men who have ever smoked, but 1.69 times (95\% CI 1.17-2.40) lower for all women who have ever smoked. Age-adjusted risk ratio for CB comparing ever smokers to never smokers was 2.29 (95\% CI 1.304.03) among men and 1.32 (95\% CI 0.95-1.82) among women; respective risk ratios for LE were 4.92 (95\% CI 1.14-21.1) and 2.45 (95\% CI 0.63-9.52). Age-adjusted RR having any of the three conditions comparing those that have smoked to never smokers was 1.66 (95\% CI 1.23-2.25) for men and 0.89 (95\% CI 0.70-1.12) for women.

There was a clear association between the number of years smoked and the risk of IHD or CB, especially among men (Table 4). Compared to those men who had been smoking up to 5 years, the age-adjusted risk of any of the three conditions was 1.04 times higher for those men who had been smoking for 6-15 years, 1.68 times higher for those who had been smoking for 16-25 years, and 2.46 times higher for those who had been smoking for more than 25 years. The corresponding age-adjusted risk ratios for women were $2.56,2.36$, and 7.11 .

\section{Population attributable risk}

After adjusting for age and years smoked, the prevalence of LE attributable to smoking was 19\% among men and $23 \%$ among women, while the attributable prevalences 


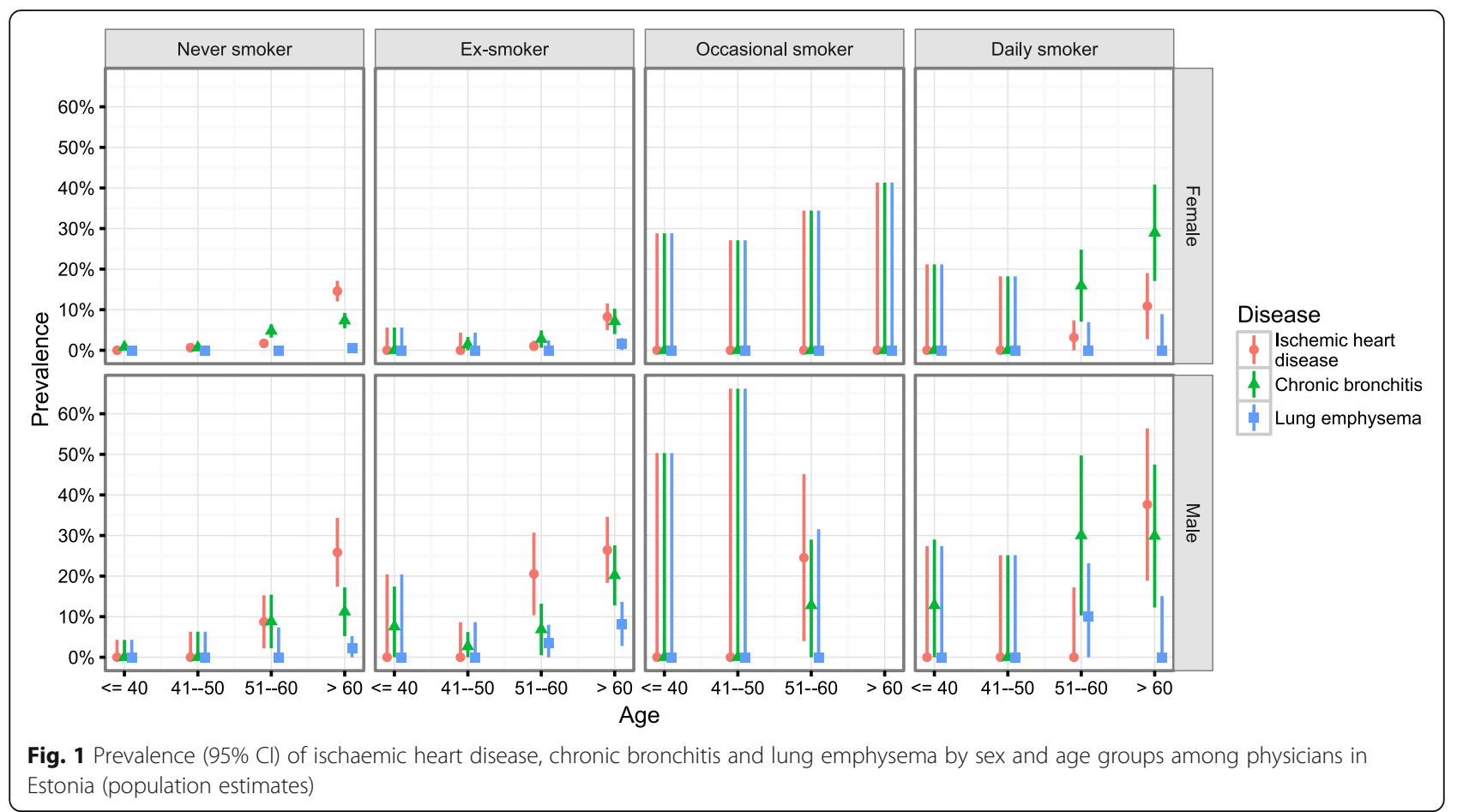

for IHD and CB were much lower ( 3 and $7 \%$ for men, 0 and $4 \%$ for women, respectively) (Table 5 ). While the difference between unadjusted and adjusted AR was $17 \%$ for IHD and $17 \%$ for $\mathrm{CB}$ among men, the respective differences were much smaller among women (3 and 4\%).

\section{Discussion}

This study focused on smoking behaviour and the relationship between smoking and IHD, CB, and LE among
Estonian physicians. The years smoked were associated with the risk for these three diseases. The risk attributable to smoking was higher for pulmonary diseases than for ischaemic heart disease.

\section{Smoking behaviour}

In Estonia $53 \%$ of male and $75 \%$ of female physicians had never smoked, while $12 \%$ of male and $5 \%$ of female physicians smoked daily in 2014. Smoking

Table 4 Age-adjusted relative risk* $(95 \% \mathrm{Cl})$ for ischaemic heart disease (IHD) and chronic bronchitis (CB) by years smoked among physicians who have ever smoked, compared to those who have smoked up to 5 years (population estimates) ${ }^{\text {a }}$

\begin{tabular}{|c|c|c|c|c|c|c|c|}
\hline \multirow[t]{3}{*}{ Condition $^{\mathrm{b}}$} & \multirow[t]{3}{*}{ Sex } & \multicolumn{3}{|l|}{ Ex-smokers } & \multicolumn{3}{|l|}{ Ever smoked $^{c}$} \\
\hline & & \multicolumn{3}{|l|}{ Years smoked } & \multicolumn{3}{|l|}{ Years smoked } \\
\hline & & $6-15$ & $16-25$ & $>25$ & $6-15$ & $16-25$ & $>25$ \\
\hline \multirow[t]{3}{*}{$\mathrm{IHD}$} & Male & $1.82(0.61-5.41)$ & $2.72(0.92-7.97)$ & $3.02(1.08-8.45)$ & $2.44(0.85-7.02)$ & $3.27(1.15-9.32)$ & $2.91(1.08-7.83)$ \\
\hline & Female & $1.83(0.60-5.56)$ & $* *$ & $5.40(2.04-14.28)$ & $1.75(0.56-5.42)$ & $* *$ & $4.32(1.59-11.75)$ \\
\hline & Total & $2.17(0.96-4.89)$ & $1.92(0.77-4.82)$ & $5.70(2.65-12.26)$ & $2.38(1.07-5.30)$ & $2.10(0.88-5.01)$ & $4.54(2.19-9.40)$ \\
\hline \multirow[t]{3}{*}{$\mathrm{CB}$} & Male & $1.08(0.31-3.74)$ & $2.04(0.60-6.97)$ & $2.31(0.73-7.31)$ & $0.79(0.30-2.06)$ & $1.17(0.42-3.25)$ & $2.10(0.86-5.16)$ \\
\hline & Female & $3.61(0.80-16.30)$ & $4.95(1.05-23.38)$ & $5.75(1.14-29.04)$ & $4.64(1.05-20.47)$ & $6.75(1.56-29.16)$ & $12.38(2.97-51.61)$ \\
\hline & Total & $2.22(0.85-5.82)$ & $3.55(1.32-9.55)$ & $4.86(1.86-12.72)$ & $1.91(0.85-4.32)$ & $2.77(1.20-6.38)$ & $5.42(2.49-11.78)$ \\
\hline \multirow[t]{3}{*}{ Any condition ${ }^{d}$} & Male & $1.02(0.45-2.33)$ & $1.91(0.87-4.17)$ & $2.65(1.31-5.36)$ & $1.04(0.51-2.12)$ & $1.68(0.85-3.33)$ & $2.46(1.35-4.50)$ \\
\hline & Female & $2.20(0.90-5.39)$ & $1.70(0.60-4.81)$ & $6.59(2.83-15.33)$ & $2.56(1.03-6.20)$ & $2.36(0.91-6.10)$ & $7.11(3.13-16.14)$ \\
\hline & Total & $1.76(0.93-3.30)$ & $2.30(1.19-4.44)$ & $7.11(3.13-16.14)$ & $1.79(1.01-3.18)$ & $2.23(1.24-4.03)$ & $5.13(3.06-8.62)$ \\
\hline
\end{tabular}

\footnotetext{
${ }^{a}$ Age-adjusted risk ratios among occasional and daily smokers were not estimable

${ }^{\mathrm{b}}$ Age-adjusted risk ratios for lung emphysema were not estimable

' Including ex-, occasional, and daily smokers

${ }^{d}$ Including ischaemic heart disease, chronic bronchitis, and lung emphysema

* Statistically significant risk ratios $(p<0.05)$ are italicized

** Not estimable
} 
Table 5 Smoking-attributable risk (AR) of ischaemic heart disease (IHD), chronic bronchitis (CB), and lung emphysema (LE) among Estonian physicians attributable to smoking (\%), with 95\% CI (population estimates)

\begin{tabular}{lllll}
\hline Sex & Condition & Unadjusted AR & AR adjusted for age & AR adjusted for age and years smoked \\
\hline Male & IHD & $20.6(18.0-23.2)$ & $8.6(5.9-11.3)$ & $3.2(2.3-4.1)$ \\
& CB & $24.2(22.3-26.5)$ & $17.5(15.3-20.1)$ & $6.9(6.0-7.8)$ \\
& LE & $53.4(47.8-61.8)$ & $47.9(41.9-57.6)$ & $18.8(17.0-22.5)$ \\
Female & Any above & $20.6(19.2-22.2)$ & $11.8(10.3-13.3)$ & $5.2(4.7-5.8)$ \\
& IHD & $-3.0(-4.2--2.1)$ & $-9.7(-10.8--8.7)$ & $-0.1(-0.7-0.4)$ \\
& CB & $8.1(7.0-9.0)$ & $4.8(3.6-5.8)$ & $4.2(3.5-4.8)$ \\
& LE & $40.9(30.7-50.0)$ & $35.5(24.3-45.4)$ & $22.6(18.5-26.9)$ \\
& Any above & $2.1(1.3-2.7)$ & $-2.7(-3.5 \ldots-2.0)$ & $1.0(0.7-1.3)$ \\
\hline
\end{tabular}

behaviour among younger (up to 40 years old) male and female physicians were more similar to each other than among physicians older than 40 years. Similar phenomenon has also been observed in other studies and has been associated with changing socioeconomic circumstances [38]. Compared to the previous similar study from 2002 [30], the prevalence of daily smoking had decreased 1.5 -fold (18\% in 2002 vs. $12 \%$ in 2014) and lifelong non-smoking had increased 1.2 -fold (43\% in 2002 vs. $53 \%$ in 2014) among male physicians, but had remained about the same among female physicians (respective proportions were 6\% in 2002 vs. $7 \%$ in 2014 , and $74 \%$ in 2002 vs. $70 \%$ in 2014). This is in line with trends in the general adult population where smoking among men has decreased faster than among women $[23,39]$. Compared to the 16-64-year old general adult population in Estonia, the prevalence of physicians who have never smoked in this study was considerably higher (by $25 \%$ among men and $22 \%$ among women) and the prevalence of daily smokers considerably lower (by 19\% among men and by $11 \%$ among women), but age-related differences correlate to those of the general population [23]. At the same time the prevalence of smoking among physicians in Estonia in 2014 was comparable with smoking among physicians in the United States and Australia in the 1980s [16, 40]. Thus, the prevalence of smoking among physicians in Estonia is still higher than in many developed countries. However, smoking prevalence among physicians in some developed countries like France, Italy and Japan has remained high with the prevalence of current smoking over $25 \%[18,41,42]$.

Our results support the hypothesis that the decline of smoking among the general population follows the decline of smoking among physicians [24, 25]. While daily smoking has decreased among Estonian physicians at least since 1982 [20], it had its peak in the general population in 1994 when the prevalence of daily smoking was 50\% among men and $21 \%$ among women [22].
Since 1994, the prevalence of daily smoking has decreased among the general population in Estonia, especially among men [21].

Interestingly, in the current study women aged between 41 and 50 years who smoked occasionally had been smoking longer time (17.9 years in average) than women aged between 51 and 60 (11.3 years). In addition to recall bias, this difference, although statistically not significant at the 0.05 significance level (results omitted), can be partially explained by the average age they started smoking. We found that women in the age group of 4150 years started smoking younger than women in the age group of 51-60. However, the time between starting smoking and the study conduct was generally longer than the number of years smoked that the subjects reported. This indicates that the subjects had had smoke-free periods. Hence, it is possible that women in the age group of 51-60 years had had more and/or longer breaks in smoking, although these data were not collected in our study.

\section{Smoking attributable diseases}

Although the prevalence of IHD and CB was similar among male and female non-smokers ( 7 and $4 \%$ among men, 4 and $3 \%$ among women), this prevalence was much higher among formerly or currently smoking men, compared to women of the same age and smoking class. This can be partially explained by the number of cigarettes smoked daily, which is higher among men in many countries [43]. Although in our study it was the similar case among daily smokers, data on the number of cigarettes smoked was not collected from occasional and ex-smokers, inhibiting to account for the intensity of smoking. Additionally, prevalence of other IHD risk factors (e.g. excess drinking) are known to be higher among men than among women in Estonia [44], but these data were not collected in our study.

Unsurprisingly, there was a clear association between the risk of smoking-related diseases and years smoked: age-adjusted risk for the IHD and CB was higher among 
those men and women who had smoked longer. These results are consistent with worldwide literature [1, 2]. Although the prevalence of LE was low $(0.6 \%)$, it is noteworthy that the majority of cases were among ex- and current smokers.

In our study, the effect of smoking was clearest in the prevalence of $\mathrm{CB}$. It was reported that for current smokers in the United States, CB was the most prevalent condition, followed by LE [45]. While tobacco smoking is the most prominent risk factor for pulmonary diseases [27], there are many additional strong risk factors for cardiovascular diseases (e.g. excessive alcohol consumption, sedentary lifestyle) [46]. However, data on those risk factors was not collected in our study.

It has been indirectly estimated that in 2015 in Estonia, $8 \%$ of deaths caused by IHD among women and $22 \%$ among men in general population were associated with tobacco smoke (corresponding proportions being similar for years of life lost and years of life lived with a disability) [27]. In our study the unadjusted attributable risks were in comparable ranges for both men (21\%) and women (about $0 \%)$. Although mortality and prevalence are directly not comparable, this similarity in the measures of smokingattributable burden of IHD in the general population compared to physicians is not surprising, as IHD has many strong risk factors besides smoking [46].

One might assume that due to cleaner working environment of physicians compared to that of an average citizen's, among physicians other risk factors (especially air pollution) would not contribute to the risk of pulmonary diseases as much as smoking would do. However, $80 \%$ of deaths caused by COPD among men and $41 \%$ among women were associated with tobacco smoke in the general population (and these proportions were similar for other measures of burden of disease) [27] while in our study the unadjusted attributable risks for pulmonary diseases were generally lower (24\% of CB among men, $8 \%$ among women; $53 \%$ of LE among men, $41 \%$ among women). Although it can partially be explained by the fact that more physicians live in cities or towns compared to the general adult population (63\%) [47], this finding was not expected and warrants further investigation.

\section{Strengths and weaknesses}

Consisting of working physicians, the study population can be considered relatively homogeneous, which reduces the effect of possible confounders (e.g. education, income). Almost half of the target population participated in the study, resulting in more precise estimates. Our sample had a definite frame (Estonian Heath Care Professionals Registry) with the information on the age and sex of physicians which allowed us to compensate for non-response by post-stratification.
There were some physicians who contacted the study team asking whether they should participate if they are non-smokers. Therefore, non-smokers might be underrepresented in the final sample. On the other hand, it is plausible that subjects who behave in a socially less desirable way (e.g. smoke daily) were less inclined to participate in this study. Physicians are perceived as most knowledgeable about the devastating effects of smoking; therefore, they may be prone to self-deception or understatement. However, the anonymity of the questionnaire supports the possibility of the responses being true. As smoking behaviour as well as health are associated with age and sex, we believe that post-stratification helped us to reduce that bias.

The questionnaire was self-administered, which may have introduced some information bias. For example, the number of years smoked might have been reported imprecisely. Considering the IHD, CB and LE, however, physicians probably have better knowledge about their health condition compared to a layman, which makes the data on self-reported health condition reasonably reliable. Nevertheless, a considerable number of physicians chose not to reveal data on having the three diseases we studied. In addition, we were not able to make certain that those who did not choose from any of the multiple choices regarding smoking-related health condition (including the option to refuse to answer) were free from those conditions. Therefore, the prevalence of IHD, CB, and LE might be underestimated. Hence it is plausible that the attributable risk estimates are underestimates as well.

Many factors may have influenced the response rate [48]. For example, physicians on sick leave or on holiday might have had more time to fill in the questionnaire. We did not study the reasons of non-response in this survey; therefore, the possible bias introduced by differential response rates is difficult to assess. However, we believe that the long response period ( 6 months) and the length of the questionnaire (four pages) has substantially decreased the risk of this bias. Additionally, the age and sex distribution of the population, often being strongly correlated with such possible factors (e.g. workload), was taken into account by post-stratification which has decreased this possible bias even more.

The cross-sectional design of this study was suitable for estimating prevalences. Although we do not know the timing of events (taking up smoking, quitting, disease occurrence), which inhibits causal interpretation of attributable risks, it has been observed that people more often quit than start smoking after getting pulmonary [49] or cardiovascular diseases [50]. Therefore, it is safe to assume that among ex- and current smokers IHD, CB, or LE occurred after being exposed to smoking. 


\section{Conclusions}

Prevalence of daily smoking was relatively low among Estonian physicians being twice lower among female physicians compared to male. Risk attributable to smoking was higher for lung emphysema and chronic bronchitis than for ischaemic heart disease, hence communicating the information about the negative effects of smoking to the people who already are at greater risk for pulmonary diseases is strongly advised.

Tobacco control policies should focus on increasing smokers' willingness to quit smoking and providing the necessary support and therapies. This would increase the likelihood of successful smoking cessation among physicians which would have major benefits to health of the general population. Further studies are required to continue monitoring the smoking behaviour among Estonian physicians.

\section{Additional file}

Additional file 1: Weighted counts. Weighted counts of study participants by sex, age, smoking status, smoking duration, presence of ischaemic heart disease, lung emphysema and chronic bronchitis. (XLSX $129 \mathrm{~kb})$

\section{Abbreviations}

AR: Attributable risk; CB: Chronic bronchitis; Cl: Confidence interval; COPD: Chronic obstructive pulmonary disease; IHD: Ischaemic heart disease; LE: Lung emphysema; RR: Relative risk

\section{Acknowledgements}

Not applicable.

\section{Funding}

The study was supported by the Estonian Ministry of Education and Research (personal funding GMVPT0299P).

\section{Availability of data and materials}

The datasets generated and/or analysed during the current study are not publicly available due to Estonian personal data protection laws (permission to publish individual-level data in public data repositories was not asked from the participants), but are available from the corresponding author on reasonable request. Weighted counts relevant to this analysis are provided in electronic supplementary material [Additional file 1].

\section{Authors' contributions}

MR contributed substantially to the conception and the design of the study, analysed data and interpreted results, drafted and critically revised the manuscript. KP contributed substantially to the conception and design of the study, interpreted results, critically revised the manuscript. Both authors read and approved the final manuscript.

\section{Ethics approval and consent to participate}

The study was approved by the Research Ethics Committee of the University of Tartu (decision no. 235/T-12). With the questionnaire the study subjects received a cover letter explaining the aim and the methods (including data protection) of the study. The cover letter explained that the participation in the study (returning at least partially filled questionnaire) would be considered to constitute informed consent. Additional written consent was not obtained.

\section{Consent for publication}

Not applicable.

\section{Competing interests}

The authors declare that they have no competing interests.

\section{Publisher's Note}

Springer Nature remains neutral with regard to jurisdictional claims in published maps and institutional affiliations.

Received: 16 June 2017 Accepted: 19 January 2018

Published online: 30 January 2018

\section{References}

1. Whisnant JP, Homer D, Ingall TJ, Baker HL Jr, O'Fallon WM, Wievers DO. Duration of cigarette smoking is the strongest predictor of severe extracranial carotid artery atherosclerosis. Stroke. 1990;21:707-14.

2. Freund KM, Belanger AJ, D'Agostino RB, Kannel WB. The health risks of smoking. The Framingham study: 34 years of follow-up. Ann. Epidemiology. 1993;3:417-24.

3. Shah RS, Cole JW. Smoking and stroke: the more you smoke the more you stroke. Expert Rev Cardiovasc Ther. 2010;8:917-32.

4. Katanoda K, Marugame T, Saika K, Satoh H, Tajima K, Suzuki T, et al. Population attributable fraction of mortality associated with tobacco smoking in Japan: a pooled analysis of three large-scale cohort studies. J Epidemiol. 2008;18:251-64

5. Bjartveit $K$, Tverdal A. Health consequences of smoking 1-4 cigarettes per day. Tob Control. 2005;14:315-20.

6. Chang CM, Corey CG, Rostron BL, Apelberg BJ. Systematic review of cigar smoking and all cause and smoking related mortality. BMC Public Health. 2015;15:390.

7. Decramer M, Janssens W, Miravitlles M. Chronic obstructive pulmonary disease. Lancet. 2012:379:1341-51.

8. Rabe KF, Watz H. Chronic obstructive pulmonary disease. Lancet. 2017;389: 1931-40.

9. Lobelo F, de Quevedo IG. The evidence in support of physicians and health care providers as physical activity role models. Am J Lifestyle Med. 2014;10: 36-52.

10. Nett LM. The physician's role in smoking cessation. A present and future agenda. Chest. 1990;97:28S-32S.

11. La Torre G, Saulle R, Unim B, Angelillo IF, Baldo V, Bergomi M, et al. Knowledge, attitudes, and smoking behaviours among physicians specializing in public health: a multicentre study. Biomed Res Int. 2014;2014: 516734.

12. Abdullah AS, Stillman FA, Yang L, Luo H, Zhang Z, Samet JM. Tobacco use and smoking cessation practices among physicians in developing countries: A literature review (1987-2010). Int J Environ Res Public Health. 2013:11(1): 429-55.

13. Meshefedjian GA, Gervais A, Tremblay M, Villeneuve D, O'Loughlin J. Physician smoking status may influence cessation counseling practices. Can J Public Heal. 2010;101:290-3.

14. Cattaruzza MS, West R. Why do doctors and medical students smoke when they must know how harmful it is? Eur J Public Health. 2013;23(2):188-9.

15. Smith DR, Leggat PA. An international review of tobacco smoking in the medical profession: 1974-2004. BMC Public Health. 2007;7:-115.

16. Smith DR, Leggat PA. The historical decline of tobacco smoking among Australian physicians: 1964-1997. Tob Induc Dis. 2008:4:13.

17. Smith DR. The historical decline of tobacco smoking among United States physicians: 1949-1984. Tob Induc Dis. 2008:4:9.

18. Smith DR, Wada K. Declining rates of tobacco use in the Japanese medical profession, 1965-2009. J Epidemiol. 2013;23:4-11.

19. Barengo NC, Sandström PH, Jormanainen VJ, Myllykangas MT. Changes in smoking prevalence among Finnish physicians 1990-2001. Eur J Public Heal. 2004;14:201-3.

20. Pärna K, Põld M, Ringmets I. Trends in smoking behaviour among Estonian physicians in 1982-2014. BMC Public Health. 2018;18:55.

21. European Health for All Database. World Health Organization Regional Office for Europe, Copenhagen. 2012. http://data.euro.who.int/hfadb. Accessed 25 Jan 2018.

22. Lipand A, Kasmel A, Tasa E, Leinsalu M, Uutela A, Puska P, et al. Health Behaviour among Estonian Adult Population, Spring 1994. Helsinki: NationalPublic Health Institute; 1995.

23. Tekkel M, Veideman T. Health Behavior among Estonian Adult Population, 2014. Tallinn: National Institute for Health Development; 2015. 
24. Kunze M. Current smoking habits in Europe. Presented at the European Conference on Tobacco Priorities and Strategies, organised by the International Union Against Cancer and the Dutch Foundation on Smoking and Health, 1-3 November 1989, The Hague, The Netherlands.

25. Davis RM. When doctors smoke. Tob Control. 1993;2:187-8.

26. GBD. Tobacco collaborators. Smoking prevalence and attributable disease burden in 195 countries and territories, 1990-2015: a systematic analysis from the global burden of disease study 2015. Lancet. 2015;2017:1885-906.

27. GBD Results Tool. Institute for Health Metrics and Evaluation. Seattle: University of Washington; 2016. http://ghdx.healthdata.org/gbd-results-tool. Accessed 25 Jan 2018

28. Lohur L, Pärna K. Arstide suitsetamine, sellealased hinnangud ja tähelepanu pööramine patsientide suitsetamisele [smoking habits, smoking related opinions and attitudes towards patients' smoking habits among physicians in Estonia]. Eesti Arst. 2016:95:285-93.

29. Tervishoiutöötajate riikliku registri pöhimäärus [Statutes of Estonian Health Care Professionals Registry]. Riigi Teataja I. 2008;(44):249.

30. Pärna K, Rahu K, Barengo NC, Rahu M, Sandström PH, Jormanainen VJ, et al. Comparison of knowledge, attitudes and behaviour regarding smoking among Estonian and Finnish physicians. Soz Praventivmed. 2005;50:378-88.

31. Levy PS, Lemeshow S. Sampling of Populations: Methods and Applications: Fourth Edition. Sampl. Popul. Methods Appl. Fourth Ed. 2011.

32. Shapla TJ, Nguyen TT, Chen JT. Multilevel attributable risk in cross-sectional studies. J Stat Comput Simul. 2009:79:39-54.

33. Walter SD. The estimation and interpretation of attributable risk in health research. Biometrics. 1976;32:829-49.

34. Booth JG, Butler RW, Peter H. Bootstrap methods for finite populations. J Am Stat Assoc. 1994;89:1282-9.

35. Centers for Disease Control and Prevention. Epi Info 3.5.3. 2013.

36. R Core Team. R: A language and environment for statistical computing. 2015.

37. Lumley T. Analysis of Complex Survey Samples. J Stat Softw. 2004;9(8):1-19.

38. Hitchman SC, Fong GT. Gender empowerment and female-to-male smoking prevalence ratios. Bull World Health Organ. 2011;89:195-202.

39. Kasmel A, Lipand A, Markina A. Health Behavior among Estonian Adult Population, Spring 2002. Tallinn: Estonian Centre for Health Education and Promotion; 2003.

40. Nelson DE, Giovino GA, Emont SL, Brackbill R, Cameron LL, Peddicord J, et al. Trends in cigarette smoking among US physicians and nurses. JAMA. 1994:271:1273-5.

41. Vecchia CL, Scarpino V, Malvezzi I, Baldi G. A survey of smoking among Italian doctors. J Epidemiol Community Health. 2000;54:320.

42. Josseran L, King G, Guilbert P, Davis J, Brücker G. Smoking by French general practitioners: behaviour, attitudes and practice. Eur J Pub Health. 2005;15:33-8.

43. Giovino GA, Mirza SA, Samet JM, Gupta PC, Jarvis MJ, Neeraj B, et al. Tobacco use in 3 billion individuals from 16 countries: an analysis of nationally representative cross-sectional household surveys. Lancet. 2012; 380:668-79.

44. Pärna K, Rahu K, Helakorpi S, Tekkel M. Alcohol consumption in Estonia and Finland: Finbalt survey 1994-2006. BMC Public Health. 2010;10:261.

45. Centers for Disease Control and Prevention (CDC). Cigarette smokingattributable morbidity_United States, 2000. MMWR Morb Mortal Wkly Rep United States. 2003;52(35):842-4.

46. World Health Organization. Cardiovascular diseases (CVDs) Fact sheet. 2017. http://www.who.int/mediacentre/factsheets/fs317/en. Accessed 25 Jan 2018

47. Statisical database. Statistics Estonia, Tallinn. 2017. http://pub.stat.ee. Accessed 25 Jan 2018

48. Edwards PJ, Roberts I, Clarke MJ, DiGuiseppi C, Wentz R, Kwan I, et al. Methods to increase response to postal and electronic questionnaires. Cochrane Database Syst Rev. 2009;(3): MR000008.

49. Westmaas JL, Newton CC, Stevens VL, Flanders WD, Gapstur SM, Jacobs EJ. Does a recent cancer diagnosis predict smoking cessation? An analysis from a large prospective US cohort. J Clin Oncol. 2015;33:1647-52.

50. Bak S, Sindrup SH, Alslev T, Kristensen O, Christensen K, Gaist D. Cessation of smoking after first-ever stroke: a follow-up study. Stroke. 2002;33:2263-9.

\section{Submit your next manuscript to BioMed Central and we will help you at every step:}

- We accept pre-submission inquiries

- Our selector tool helps you to find the most relevant journal

- We provide round the clock customer support

- Convenient online submission

- Thorough peer review

- Inclusion in PubMed and all major indexing services

- Maximum visibility for your research

Submit your manuscript at www.biomedcentral.com/submit

) Biomed Central 